\title{
Vitamin D status in acute ischemic stroke: relation to initial severity and short-term outcome
}

\author{
E. Fahmy ${ }^{1}$, S. Sharaf ${ }^{2}$, H. Helmy ${ }^{1 *}$ and S. Sherif ${ }^{1}$
}

\begin{abstract}
Background: A growing body of evidence indicated that vitamin D has a potential protective role against neurovascular injury. Low serum vitamin $D$ has been associated with increased risk for incident stroke and stroke fatality.

Objective: This study aimed to investigate vitamin D status among acute ischemic stroke patients and examine its relation to initial severity and short-term outcome.

Subjects and methods: Forty-eight acute ischemic stroke patients and 48 matched healthy control subjects participated in the study. Subjects were divided according to vitamin D level into deficient, insufficient, and sufficient groups. National Institute of Health Stroke Scale (NIHSS) on admission and after $72 \mathrm{~h}$ and modified Rankin Scale (mRS) on discharge and after 3 months were performed for all patients.

Results: Stroke patients had significantly lower serum vitamin D levels compared to healthy subjects. Vitamin D deficiency and insufficiency were significantly prevalent among patients compared to healthy controls. Significant negative correlation was detected between serum vitamin D and NIHSS scores on admission and after $72 \mathrm{~h}$. Significant negative correlation was also detected between serum vitamin D and mRS scores on discharge and after 3 months. An increased risk of stroke of 2.88 times was found in patients with insufficient vitamin $D$ in comparison to sufficient subgroup, and this likelihood increases to be 13.78 times in the deficient compared to sufficient subgroups.
\end{abstract}

Conclusion: Vitamin D deficiency increases the risk of acute ischemic stroke and is associated with increased initial stroke severity and worse short-term outcome.

Keywords: Acute ischemic stroke, Vitamin D, Stroke severity, Stroke outcome

\section{Introduction}

Vitamin D deficiency has been identified as a common problem in stroke survivors with an estimated prevalence of 71\% [1]. Reasons for Geographic and Racial Differences in Stroke (REGARDS) study of more than 16,000 black and white patients showed that those who lived in areas that had shorter exposure to sunlight has a $56 \%$ increased risk of stroke, and it showed that persons with higher level of vitamin $\mathrm{D}$ in their diet had a decreased risk of stroke and cognitive impairment [2].

* Correspondence: drhananelgendy76@gmail.com

'Department of Neurology, Cairo University, Cairo, Egypt

Full list of author information is available at the end of the article
The prevalence of osteoporosis in post stroke survivors [3] as well as the identification of vitamin $\mathrm{D}$ receptors (VDR) and 1a-OHase activity in the brain [4] paved the way for more studies exploring the relationship between vitamin D status and stroke.

Large epidemiological studies indicated an association between vitamin D status and risk of stroke [5]. However, the relationship between different vitamin D states in acute ischemic stroke patients as well as exploring vitamin $\mathrm{D}$ as an independent risk factor for acute ischemic stroke need more elucidation [5-8].

Studies have also shown that serum vitamin D is associated with outcome after ischemic stroke. This provides a rationale to further investigate vitamin $\mathrm{D}$ as a 
Table 1 Stroke severity on admission and after $72 \mathrm{~h}$ regarding NIHSS score

\begin{tabular}{lllllll}
\hline & Number & Mean & Std. deviation & Median & Minimum & Maximum \\
\hline Initial NIHSS score & 48 & 11.375 & 4.8361 & 11.000 & 2.0 & 28.0 \\
NIHSS score after $72 \mathrm{~h}$ & 48 & 8.937 & 5.0882 & 8.000 & 1.0 & 28.0
\end{tabular}

NIHSS National Institute of Health Stroke Scale

biomarker for cerebral ischemic vulnerability and identify patients at high risk for poor post stroke outcome and the potential of vitamin D supplementation for secondary stroke prophylaxis [9].

This study was designed to assess vitamin D status among acute ischemic stroke patients and examine its relation to initial stroke severity and short-term outcome.

\section{Subjects and methods}

This is a case-control study conducted on 96 subjects (48 acute ischemic stroke patients and 48 matched healthy subjects). Patients were selected from the stroke unit of the Neurology Department, Cairo University hospitals, in the period from October to December 2017. An informed consent was taken from the patients prior to participation to ensure complete satisfaction. The study was approved by the ethical committee of the Neurology Department, Faculty of Medicine, Cairo University.

Included in this study are patients with acute ischemic stroke diagnosed clinically and evidenced by neuroimaging (computed tomography or magnetic resonance imaging of the brain), age $\geq 20$ years.

Exclusion criteria were intracerebral hemorrhage, endocrinal disorders that may affect bone health (thyroid, parathyroid, and adrenal disorders), chronic illness that may affect bone health, patients receiving drugs that may affect bone health (corticosteroids, chemotherapy, $\mathrm{H} 2$ blockers, or proton pump inhibitors), patients receiving vitamin $\mathrm{D}$ supplementation, and pregnant, lactating, and menopausal females.

Patients were submitted to:

- Thorough clinical assessment

- Assessment of initial stroke severity: using the National institute of Health Stroke Scale (NIHSS) on admission and after $72 \mathrm{~h}$. The scale consists of five score sections, score 0 (no stroke symptoms), score 1-4 (minor stroke), score 5-15 (moderate stroke), score 16-20 (moderate to severe stroke), and score 21-42 (severe stroke) [10]

- Assessment of the functional outcome: using the modified Rankin Scale (mRS) on discharge and after 3 months. The scale runs from 0 to 6 , running from perfect health without symptoms to death. Favorable (good) outcome is indicated by $\mathrm{mRS} \leq 2$, while poor outcome is indicated by $\mathrm{mRS} \geq 3$ [11].
- Routine laboratory workup included complete blood count, liver function tests, kidney function tests, fasting blood sugar, and electrolytes (including sodium, potassium, calcium, and phosphorus levels)

- Serum vitamin D assay: using enzyme-linked immunosorbent assay (ELISA). Venous blood samples were collected then centrifuged to get serum. The kit was used for the quantitative measurement of total $25-\mathrm{OH}$ vitamin $\mathrm{D}_{3}$ in serum. The assay utilizes a monoclonal antibody that binds to $25-\mathrm{OH}$ vitamin $\mathrm{D}_{3}$. Assay calibrators, controls, and test samples are added directly to wells of a microtiter plate that is coated with specific anti-25-OH-vitamin $\mathrm{D}_{3}$ antibody. A buffer designed to release vitamin $\mathrm{D}$ from binding proteins is then added to the wells. For the detection of the immune-complex, the well is incubated with a substrate solution in a timed reaction, which is terminated with acidic reagent (ELISA stop solution). The absorbance is then measured in a spectrophotometric reader. The enzymatic activity of the immune-complex bound to the wall of each microtiter well is inversely proportional to the amount of total $25-\mathrm{OH}$ vitamin $\mathrm{D}_{3}$ in the test sample. A calibration curve is generated by plotting the absorbance versus the respective vitamin D concentration for each calibrator on a four-parameter or point-topoint curve fitting: vitamin D sufficiency $\geq 30 \mathrm{ng} / \mathrm{ml}$, vitamin D insufficiency $10-29 \mathrm{ng} / \mathrm{ml}$, and vitamin D deficiency $<10 \mathrm{ng} / \mathrm{ml}[12]$.

\section{Statistical analysis}

Data were analyzed using the Statistical Program for Social Science (SPSS) version 22, IBM Corp., Chicago, USA, 2013. Quantitative data were expressed as mean \pm standard deviation (SD). Qualitative data were expressed as frequency and percentage. For quantitative data, independent $t$ test was used to compare between two independent variables with parametric data and paired $t$ test to compare between two dependent variables. A one-way analysis of variance (ANOVA) was used to compare between more than two variables. Post hoc was used to test possible combinations of groups to determine where the significant differences are located. For qualitative data, chi-square was used for differences between proportions and Fisher exact for variables with small expected numbers. Pearson correlation coefficient was used for correlation between variables. A logistic regression analysis was performed to evaluate the 
Table 2 Comparison of mean serum vitamin D level between study subgroups

\begin{tabular}{lllllll}
\hline & \multicolumn{2}{l}{ Study group } & & \multirow{2}{l}{$\begin{array}{l}p \\
\text { value }\end{array}$} \\
\cline { 2 - 3 } & \multicolumn{2}{l}{ Controls } & & \multicolumn{2}{l}{ Patients } & \\
\cline { 2 - 3 } & Count & $\%$ & & Count & $\%$ & \\
\hline Vit D status & & & & & & \\
Deficient & 3 & 6.3 & & 15 & 31.3 & $0.002^{* *}$ \\
Insufficient & 19 & 39.6 & & 20 & 41.7 & \\
Sufficient & 26 & 54.2 & & 13 & 27.1 & \\
Total & 48 & 100.0 & 48 & 100.0 & \\
\hline
\end{tabular}

**Highly significant

independence of vitamin $\mathrm{D}$ role in the disease status. $p$ value $<0.05$ was considered significant, and $p$ value $<$ 0.01 was considered highly significant.

\section{Results}

The age of patients ranged from 20 to 80 years with a mean of $56.81 \pm 13.76$ years, while the age of control subjects ranged from 31 to 74 years with a mean of $54.77 \pm 12.47$ years $(p$ value $=0.37)$. Among patients and controls, $32(66.7 \%)$ were males and 16 (33.3\%) were females $(p$ value $=1)$.

Thirty-four patients $(70.8 \%)$ were hypertensive, 19 patients (39.5\%) were diabetic, 17 patients $(35.4 \%)$ had ischemic heart disease, and 9 patients (18.8\%) were current smokers.

On presentation, the NIHSS scores ranged from 2 to 28 with a mean of $11.375 \pm 4.836$. Three patients $(6.25 \%)$ had mild stroke, 34 patients $(70.88 \%)$ had moderate stroke, 10 patients $(20.83 \%)$ had moderate/severe stroke, and 1 patient (2.08\%) had severe stroke.

After $72 \mathrm{~h}$, the NIHSS scores ranged from 1 to 28 with a mean of $8.937 \pm 5.088$. Nine patients $(18.75 \%)$ had mild stroke, 33 patients $(68.75 \%)$ had moderate stroke, 5 patients $(10.41 \%)$ had moderate/severe stroke, and 1 patient $(2.08 \%)$ had severe stroke (Table 1$)$.

On discharge, mRS scores ranged from 1 to 5 with a mean of $3.667 \pm 1.09$. Seven patients (14.6\%) had good outcome whereas 41 patients (85.4\%) had poor outcome. After 3 months, mRS scores ranged from 1 to 6 with a mean of $3.417 \pm 1.44$. Twelve patients $(25 \%)$ had good outcome; however, 36 patients $(75 \%)$ had poor outcome.

Table 3 Comparison between patient subgroups regarding NIHSS scores

\begin{tabular}{lll}
\hline Patient subgroups & Initial NIHSS score & $p$ value \\
\hline Deficient & $13.07 \pm 5.725$ & $0.0039^{* *}$ \\
Insufficient & $11.90 \pm 3.432$ & \\
Sufficient & $8.62 \pm 4.735$ & \\
\hline
\end{tabular}

NIHSS National Institute of Health Stroke Scale **Highly significant
Table 4 Comparison between patient subgroups regarding mean mRS scores on discharge and after 3 months

\begin{tabular}{lll}
\hline Patient subgroups & $\mathrm{mRS}$ score on discharge & $\mathrm{mRS}$ score after 3 months \\
\hline Deficient & $4.07 \pm 1.100$ & $4.60 \pm 1.352$ \\
Insufficient & $3.85 \pm 0.988$ & $3.40 \pm 1.046$ \\
Sufficient & $2.92 \pm 0.954$ & $2.08 \pm 0.760$ \\
$p$ value & $0.011^{*}$ & $0.000^{* *}$ \\
\hline $\begin{array}{l}\text { mRS modified Rankin Scale } \\
\text { *Significant } \\
\text { **Highly significant }\end{array}$ &
\end{tabular}

Serum vitamin $\mathrm{D}$ level: In patients, serum vitamin $\mathrm{D}$ level ranged from 2.7 to $42 \mathrm{ng} / \mathrm{ml}$ with a mean of 21.260 $\pm 12.54 \mathrm{ng} / \mathrm{ml}$. In controls, serum vitamin D levels ranged from 4 to $60 \mathrm{ng} / \mathrm{ml}$ with a mean of $28.72 \pm$ $11.284 \mathrm{ng} / \mathrm{ml}$. A statistically significant difference was found between the two groups as regards mean serum vitamin D level, being significantly lower in stroke patients $(p$ value $=0.003)$.

According to vitamin D status, patients and controls were sub-divided into three subgroups: deficient (vitamin D levels < $10 \mathrm{ng} / \mathrm{ml}$ ), insufficient (vitamin D levels $10-29 \mathrm{ng} / \mathrm{ml}$ ), and sufficient (vitamin D levels $\geq 30 \mathrm{ng} /$ ml) [12]. A statistically significant difference was also detected between subgroups of patients and controls regarding vitamin D status ( $p$ value $=0.002)$ (Table 2$)$.

On comparing NIHSS score between patient subgroups, there was a statistically significant difference detected between patient subgroups regarding initial scores of NIHSS, being significantly higher in the deficient group $(p=0.0039)$. Post hoc analysis revealed a statistically significant difference between deficient and insufficient groups compared to sufficient group ( $p$ value $=$ $0.014,0.042$ respectively); however, the difference between deficient and insufficient groups was insignificant $(p$ value $=0.462)$ (Table 3$)$.

On discharge, a statistically significant difference was detected between patient subgroups regarding mean scores of mRS, being significantly higher in the deficient

Table 5 Relation between serum vitamin D and stroke severity on presentation and after $72 \mathrm{~h}$ by NIHSS

$25(\mathrm{OH})$ vit $\mathrm{D}(\mathrm{ng} / \mathrm{ml})$

NIHSS score on admission

$\begin{array}{ll}\text { Pearson correlation } & -0.286 \\ \text { Sig. (two-tailed) } & 0.049^{*}\end{array}$

N 48

NIHSS score after $72 \mathrm{~h}$

$\begin{array}{ll}\text { Pearson Correlation } & -0.357\end{array}$

Sig. (two-tailed) $0.013^{*}$

N 48

NIHSS National Institute of Health Stroke Scale *Significant 


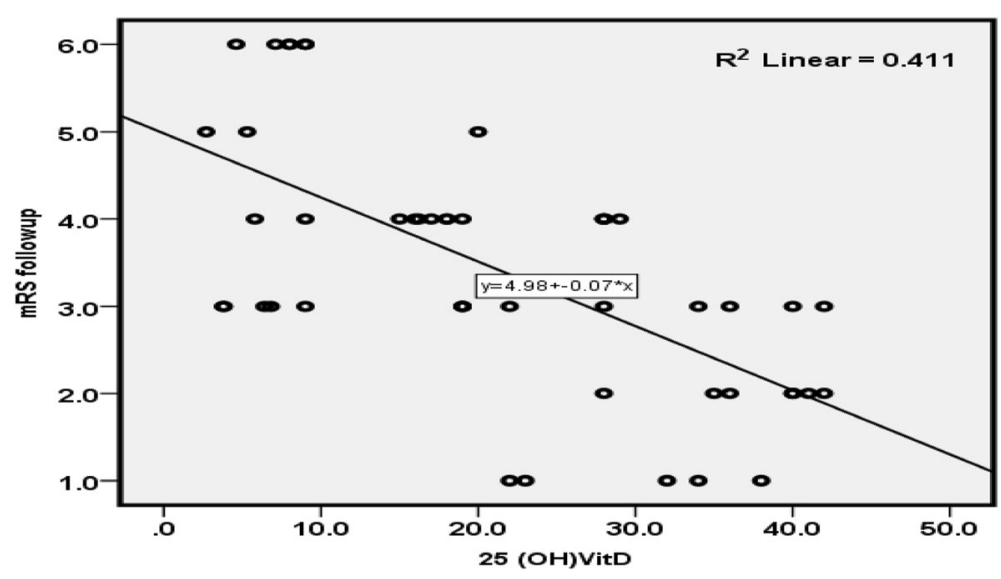

Fig. 1 Correlation between serum vitamin D level and mRS (modified Rankin Scale) score after 3 months

group $(p=0.011)$. Post hoc analysis revealed a statistically significant difference between deficient and insufficient groups compared to the sufficient group $(p=0.005$, 0.014 respectively); however, the difference between deficient and insufficient groups was insignificant $(p$ value $=$ 0.535).

After 3 months, a statistically highly significant difference was detected between patient subgroups regarding mean scores of $\mathrm{mRS}$, being significantly higher in the deficient group $(p=0.000)$. Post hoc analysis revealed a statistically high significant difference between deficient and insufficient groups ( $p$ value $=0.002)$ and between deficient and sufficient groups $(p=0.000)$ as well as between insufficient and sufficient groups $(p=0.001)$ (Table 4).

A significant negative correlation was found between serum vitamin D level and NIHSS score on presentation and after $72 \mathrm{~h}$ ( $p=0.049,0.013$ respectively) (Table 5).

A highly significant negative correlation was found between serum vitamin $\mathrm{D}$ level and score of mRS on discharge and after 3 months ( $p=0.008,0.000$ respectively) (Fig. 1).

A logistic regression analysis was performed to evaluate the independence of vitamin D role in the disease status apart from differences of age, gender distribution, and vascular risk factors. Vitamin D was found contributing to disease status (severity and outcome) independent of age, gender, and vascular risk factors. Likelihood of stroke severity is 2.88 if vitamin D is insufficient compared to sufficient. The likelihood increased to more than 13 times if the person is deficient OR=13.78. Likelihood of having a poor outcome is 10.968 times more with each nanogram-per-milliliter decrease in vitamin $D$ levels OR $=10.968$ (Table 6).

\section{Discussion}

Vitamin D has a potential protective role against neurovascular injury. Specifically, low serum vitamin D has been associated with increased risk for incident stroke and stroke fatality [13]. Poor vitamin D status in stroke patients has also been found to be closely related not only to increased risk for future cerebrovascular accident but also to functional impairment in stroke [6].

In this study, a statistically significant difference was found in mean serum vitamin $D$ between patients and controls, being significantly lower in stroke patients. Moreover, there was a significant difference between patient and control subgroups distributed according to

Table 6 Logistic regression model for factors affecting stroke severity and outcome

\begin{tabular}{|c|c|c|c|c|c|c|c|}
\hline & \multirow[t]{2}{*}{ Vitamin D } & \multirow[t]{2}{*}{$B$} & \multirow[t]{2}{*}{ S.E. } & \multirow{2}{*}{$\begin{array}{l}p \\
\text { value }\end{array}$} & \multirow[t]{2}{*}{ OR } & \multicolumn{2}{|c|}{$95 \% \mathrm{Cl}$ for OR } \\
\hline & & & & & & Lower & $\overline{\text { Upper }}$ \\
\hline \multirow[t]{4}{*}{ Stroke severity } & Sufficient & & & 0.003 & & & \\
\hline & Insufficient & 1.059 & 0.523 & $0.043^{*}$ & $2.884^{*}$ & 1.035 & 8.036 \\
\hline & Deficient & 2.623 & 0.780 & $0.001^{*}$ & $13.780^{*}$ & 2.988 & 63.553 \\
\hline & Constant & -0.049 & 0.394 & 0.902 & 0.953 & & \\
\hline \multirow[t]{2}{*}{ Stroke outcome } & vitD.gp(1) & 2.395 & 1.036 & 0.021 & 10.968 & 1.438 & 83.630 \\
\hline & Constant & -2.726 & 1.171 & 0.020 & 0.065 & & \\
\hline
\end{tabular}

$\mathrm{Cl}$ confidence interval, $O R$ odds ratio 
vitamin D status, where vitamin D deficiency and insufficiency were more significantly encountered in stroke patients compared to control subjects who mostly had a sufficient vitamin D status. This goes in agreement with previous studies that showed a modest association between low $25(\mathrm{OH})$ vitamin D levels and risk of incident ischemic stroke $[7,8,14,15]$.

Findings of this study also came in agreement with Brondum-Jacobsen and colleagues [16] who showed in their original study and a meta-analysis study with a large population-based prospective approach, a stepwise increase of symptomatic ischemic stroke with decreasing plasma 25-hydroxyvitamin D concentrations. Moreover, another study [17] examined the association of $25(\mathrm{OH})$ vitamin D with incident stroke in a cohort of black and white adults $\geq 45$ years of age and showed that vitamin D deficiency is a risk factor for incident stroke and the strength of this association does not appear to differ by race.

The current study revealed a significant difference between patient subgroups regarding stroke severity on presentation where lower vitamin D levels were associated with higher NIHSS scores indicating severer strokes. A strong negative correlation was also detected between vitamin $\mathrm{D}$ status and initial stroke severity. A strong negative correlation was also found between vitamin D status and NIHSS scores after $72 \mathrm{~h}$, confirming the consistent relation between vitamin $\mathrm{D}$ and stroke severity This came in agreement with previous studies which showed that lower $25(\mathrm{OH})$ vitamin D levels were independently associated with higher clinical severity [18-20].

Previous studies have established the role of vitamin D in predicting short-term outcome after stroke, the lower the vitamin $\mathrm{D}$ levels, the worse the outcome following stroke $[7,15,16,18,19,21,22]$. In accordance to these studies, we found that mRS on discharge and after 3 months showed a highly significant difference between patient subgroups. A strong negative correlation was also detected between vitamin D status and mRS on discharge and after 3 months.

A logistic regression analysis revealed independence of vitamin $\mathrm{D}$ in the disease status where vitamin $\mathrm{D}$ insufficiency increases the risk of stroke severity by 2.884 times whereas vitamin D deficiency increases the severity 13.78 times. These findings came in agreement with Makariou and colleagues [6], also Zhou and colleagues [5]. Another logistic regression analysis was done to evaluate the independence of vitamin $\mathrm{D}$ in the disease outcome. The likelihood of having a poor outcome is 10.5 with each nanogram-per-milliliter reduction in vitamin D levels.

In view of the findings of this study, it could be concluded that vitamin D deficiency is associated with initial severity of acute ischemic stroke and a predictor for a worse short-term outcome. These results warrant considering vitamin D supplementation in primary prevention of stroke in patients with vascular risk factors and in secondary prevention in patients who develop stroke to minimize disability and improve functional outcome.

\section{Recommendations}

Based on the findings of this study, vitamin D supplementation is suggested in the primary prevention of stroke in patients with vascular risk factors. Future research is needed to study the relation between vitamin D receptor polymorphisms and acute ischemic stroke and investigate the effect of vitamin D supplementation on functional outcome following ischemic stroke.

\section{Abbreviations}

ANOVA: One-way analysis of variance; ELISA: Enzyme-linked immunosorbent assay; mRS: Modified Rankin Scale; NIHSS: National Institute of Health Stroke; SD: Standard deviation; SPSS: Statistical Program for Social Science

\section{Acknowledgements \\ The authors acknowledge subjects for this participation and cooperation.}

\section{Funding}

Personnel Funding by the authors themselves.

\section{Availability of data and materials}

The datasets generated and/or analyzed during the current study are not publicly available due to current Cairo University regulations \& Egyptian legislation but are available from the corresponding author on reasonable request and after institutional approval.

\section{Authors' contributions \\ $\mathrm{EF}$ and $\mathrm{HH}$ contributed to the research idea and conception. $\mathrm{EF}, \mathrm{HH}, \mathrm{SS}$, and SS contributed to the data acquisition, data analysis, interpretation, and manuscript writing and review. All authors read and approved the final manuscript.}

Ethics approval and consent to participate

The aim and procedures of the study were explained to every participant and an informed consent was obtained before being enrolled in the study. The study was approved by the ethical committee of the Faculty of Medicine, Cairo University has allowed this study. Date of approval on 15th August 2017 and final approval of whole work on 17th of July 2018, but the reference number of approval is not available.

Consent for publication

Not applicable.

\section{Competing interests}

The authors declare that they have no competing interests. We declare that the research was conducted in the absence of any commercial relationships that could be constructed as a potential conflict of interest.

\section{Publisher's Note}

Springer Nature remains neutral with regard to jurisdictional claims in published maps and institutional affiliations.

\section{Author details}

${ }^{1}$ Department of Neurology, Cairo University, Cairo, Egypt. ${ }^{2}$ Clinical Pathology, Cairo University, Cairo, Egypt. 
Received: 9 October 2018 Accepted: 5 February 2019

Published online: 21 February 2019

\section{References}

1. Gupta A, Prabhakar S, Modi M, Bhadada SK, Kalaivani M, Lal V, et al. Effect of vitamin D and calcium supplementation on ischaemic stroke outcome: a randomised controlled open-label trial. Int J Clin Pract. 2016;70(9):764-70.

2. Nair R, Maseeh A. Vitamin D: the "sunshine" vitamin. J Pharmacol Pharmacother. 2012;3(2):118-26.

3. Uluduz D, Adil MM, Rahim B, Gilani WI, Rahman HA, Gilani SI, et al. Vitamin $D$ deficiency and osteoporosis in stroke survivors: an analysis of National Health and Nutritional Examination Survey (NHANES). J Vasc Interv Neurol. 2014;7(1):23-8.

4. Eyles DW, Smith S, Kinobe R, Hewison M, McGrath JJ. Distribution of the vitamin $\mathrm{D}$ receptor and 1 a-hydroxylase in human brain. J Chem Neuroanat. 2005;29(1):21-30.

5. Zhou R, Wang M, Huang H, Li W, Hu Y, Wu T. Lower vitamin D status is associated with an increased risk of ischemic stroke: a systematic review and meta-analysis. Nutrients. 2018;10(3):277.

6. Makariou SE, Michel P, Tzoufi MS, Challa A, Milionis HJ. Vitamin D and stroke: promise for prevention and better outcome. Curr Vasc Pharmacol. 2014;12(1):117-24.

7. Park KY, Chung PW, Kim YB, Moon HS, Suh BC, Won YS, et al. Serum vitamin $D$ status as a predictor of prognosis in patients with acute ischemic stroke. Cerebrovasc Dis. 2015;40(1-2):73-80.

8. Sun Q, Pan A, Hu FB, Manson JE, Rexrode KM. 25-Hydroxyvitamin D levels and the risk of stroke: a prospective study and meta-analysis. Stroke. 2012; 43(6):1470-7.

9. Turetsky A, Goddeau RP Jr, Henninger N. Low serum vitamin D is independently associated with larger lesion volumes after ischemic stroke. J Stroke Cerebrovasc Dis. 2015;24(7):1555-63.

10. Kasner SE. Clinical interpretation and use of stroke scales. Lancet Neurol. 2006;5(7):603-12.

11. Sulter G, Steen C, De Keyser J, De Keyser J. Use of the Barthel index and modified Rankin scale in acute stroke trials. Stroke. 1999;30(8):1538-41.

12. Kennel KA, Drake MT, Hurley DL. Vitamin D deficiency in adults: when to test and how to treat [Elsevier.]. Mayo Clin Proc 2010:85(8):752-757.

13. Carrelli AL, Walker MD, Lowe H, McMahon DJ, Rundek T, Sacco RL, et al. Vitamin $D$ deficiency is associated with subclinical carotid atherosclerosis: the Northern Manhattan study. Stroke. 2011;42(8):2240-5.

14. Poole KE, Loveridge N, Barker PJ, Halsall DJ, Rose C, Reeve J, et al. Reduced vitamin D in acute stroke. Stroke. 2006:37(1):243-5.

15. Alfieri DF, Lehmann MF, Oliveira SR, Flauzino T, Delongui F, de Araújo MC, et al. Vitamin D deficiency is associated with acute ischemic stroke, C-reactive protein, and short-term outcome. Metab Brain Dis. 2017;32(2):493-502.

16. Brøndum-Jacobsen P, Nordestgaard BG, Schnohr P, Benn M. 25Hydroxyvitamin $D$ and symptomatic ischemic stroke: an original study and meta-analysis. Ann Neurol. 2013;73(1):38-47.

17. Judd SE, Morgan CJ, Panwar B, Howard VJ, Wadley VG, Jenny NS, et al. Vitamin D deficiency and incident stroke risk in community-living black and white adults. Int J Stroke. 2016;11(1):93-102.

18. Daubail B, Jacquin A, Guilland JC, Khoumri C, Aboa-Eboulé C, Giroud M, et al. Association between serum concentration of vitamin D and 1-year mortality in stroke patients. Cerebrovasc Dis. 2014;37(5):364-7.

19. Tu WJ, Zhao SJ, Xu DJ, Chen H. Serum 25-hydroxyvitamin D predicts the short-term outcomes of Chinese patients with acute ischaemic stroke. Clin Sci (Lond). 2014;126(5):339-46.

20. Li YY, Wang YS, Chen Y, Hu YH, Cui W, Shi XY, et al. Association of serum 25 $(\mathrm{OH}) \mathrm{D}$ levels with infarct volumes and stroke severity in acute ischemic stroke. J Nutr Health Aging. 2018;22(1):97-102.

21. Wang $Y$, Ji H, Tong $Y$, Zhang ZB. Prognostic value of serum 25 -hydroxyvitamin D in patients with stroke. Neurochem Res. 2014;39(7):1332-7.

22. Xu T, Zhong C, Xu T, Peng Y, Bu X, Chen CS, et al. Serum 25-hydroxyvitamin $D$ deficiency predicts long-term poor prognosis among ischemic stroke patients without hyperglycaemia. Clin Chim Acta. 2017:471:81-5.

\section{Submit your manuscript to a SpringerOpen ${ }^{\circ}$ journal and benefit from:}

- Convenient online submission

- Rigorous peer review

- Open access: articles freely available online

- High visibility within the field

- Retaining the copyright to your article

Submit your next manuscript at $\boldsymbol{\nabla}$ springeropen.com 